\title{
Compreendendo o Passivo
}

\section{Resumo}

O presente artigo tem por finalidade demonstrar o quanto é importante a utilização dos relatórios contábeis perante as empresas e, de maneira mais implícita, esclarecer sobre o grupo do balanço patrimonial denominado PASSIVO. Esclarece também aos usuários e iniciantes que no mesmo são registradas as obrigações com seus valores atualizados na data presente e com a inclusão dos passivos contingentes, tais como ações trabalhistas e cíveis com seus valores quando devidamente reconhecidos. E, quando não for possível esse reconhecimento, os passivos contingentes têm que ser citados em notas explicativas, de forma que o usuário da contabilidade tenha de maneira geral as informações corretas e transparentes.

\section{Abstract}

This present article objective is to show how much is important the utilization of the accounting reports by companies principally for clarifying the assets balance group named PASSIVE. Users and initiates are also clarified that in the accounting report are registered duties (or debentures) with values updated at right time and with the inclusion of contingent passives and civil an laborite actions as well where its values are duly recognized. When it will not be possible to recognize this relationship the contingent passives have to be quoted in explicative notes so that the accountability users have the correct and clear information.

\section{1- Introdução}

\section{A Contabilidade - conceito e objeto}

É a ciência que estuda o patrimônio sob o ponto de vista econômico e financeiro, observando seus aspectos quantitativos e específicos e as variações por ele sofridas, e tem por objeto um patrimônio administrável, considerado do ponto de vista econômico e financeiro, e ainda seus aspectos quantitativos e específicos.

Os principais meios utilizados pela contabilidade são:

- o registro dos fatos contábeis;

- $\quad$ a aplicação de cálculo financeiro;

- a demonstração expositiva da situação do patrimônio em dado momento;

- a demonstração expositiva do resultado econômico (lucro ou prejuízo) apurado em determinado período administrativo;

- a análise e a interpretação da situação do patrimônio e do resultado econômico apurado.

Através desses meios, a contabilidade atinge o seu fim, que é o de oferecer aos administradores do patrimônio as informações necessárias para que possam exercer com eficiência suas funções.

O registro dos fatos contábeis é o lançamento, nos livros e formulários próprios, de todas as ocorrências relativas aos elementos que formaram o patrimônio.

\section{Finalidades e funções}

A principal finalidade da contabilidade é, pois, colaborar com os administradores do patrimônio no exercício de suas funções. A Contabilidade permite a melhor administração dos bens, pois mostra se o trabalho está, ou não, sendo compensado, se o custo do produto é

\footnotetext{
*Mestrando em Controladoria e Contabilidade Estratégica Fecap/Facesp. Bacharel em Administração de Empresas e Ciências Contábeis. Pós-graduado em Finanças. Professor universitário.

**Mestrando em Controladoria e Contabilidade Estratégica Fecap/Facesp. Empresário do ramo contábil. Professor universitário, Bacharel em Ciências Contábeis.
} 
baixo ou alto, se houve lucro ou prejuízo com a venda e se as despesas estão sendo excessivas.

Pode-se observar claramente que, na empresa, sua principal função é a mensuração do lucro e o reporte da posição patrimonial em determinados momentos. De qualquer maneira, o afã de acompanhar a evolução do patrimônio das entidades está presente na Contabilidade. Teve de valer-se a Contabilidade, portanto, de conceitos trazidos da economia, como capital, renda, consumo (despesa); outros conceitos derivam do Direito e outros ainda da Administração, apenas para citar três das principais ligações contábeis. Isto dá uma idéia da dificuldade da missão contábil. Por outro lado, as formas de atividade econômica têm sido amplamente influenciadas, no decurso dos tempos, pelas instituições sociais, políticas, religiosas e até por usos e costumes de cada época.

No início do Século XV, era comum aparecer no ativo imobilizado das empresas uma conta do tipo "Maria - Nossa Escrava", pois, efetivamente, os escravos eram propriedade do empreendimento e eram registrados pelo valor de aquisição. Por outro lado, raramente apareciam consignadas na demonstração de resultados receitas ou despesas de juros, pois tal prática era severamente condenada pela Igreja, na época.

Portanto, deve-se entender que certos conceitos que regem a Contabilidade são mutáveis, parcial ou totalmente, no tempo e no espaço, adaptando-se às peculiaridades econômicas, institucionais, políticas e sociais de cada época e, às vezes, observando peculiaridades de cada país. É claro que outros são imutáveis, como o princípio da dualidade, cuja evidenciação contábil se resume no método das partidas dobradas. Ainda assim, a forma de consubstanciar as partidas dobradas, por exemplo, pode-se alterar. Um lançamento contábil pode ser feito em forma de registro no livro Diário, no Razão de folhas soltas, numa representação didática de razonete em $\mathrm{T}$, num cartão perfurado ou mesmo numa matriz.

\section{O Patrimônio}

É o conjunto de bens, direitos e obrigações, mensuráveis em dinheiro, pertencentes a uma pessoa física ou jurídica. Assim, o patrimônio tem as seguintes características:

Personalidade: Pessoa Física ou Jurídica.

Componentes: bens, direitos e obrigações.

Função: externa o grau de riqueza do proprietário.

Mensuração: para efeito contábil, um item só será componente do patrimônio se for mensurável em dinheiro.

Mutações: é normal o patrimônio estar em constante mutação, provocando um acréscimo ou decréscimo, conforme a qualidade de sua administração e fatores externos.

O patrimônio pode pertencer a:

a) Pessoa Física: o próprio ser humano. Sua personalidade civil começa com o seu nascimento, conforme o artigo $4^{\circ}$ do Código Civil Brasileiro.

b) Pessoa Jurídica: serve para designar a existência legal de uma sociedade, corporação, associação ou instituição, que auferiu o direito de ter vida própria e isolada das pessoas físicas que a constituíram.

A pessoa jurídica é considerada existente conforme a lei, quando os seus atos constitutivos forem registrados nos órgãos competentes, sendo necessário o mesmo procedimento para seu encerramento.

O patrimônio, como vimos, é constituído por três elementos: bens, direitos e obrigações; agora, na verdade, a Lei 6.404/76 (Lei das Sociedades Anônimas, aplicável às demais sociedades), no artigo 179 , dispõe que os elementos patrimoniais são: direitos e obrigações, o que podemos representar da seguinte maneira:

\begin{tabular}{|c|c|}
\hline ATIVO & PASSIVO \\
\hline DIREITOS & OBRIGAÇÕES \\
\hline
\end{tabular}


Por fim, podemos concluir que no Ativo da empresa pode haver bens propriamente ditos e direitos sobre bem; daí, o meio contábil, ter firmado que de maneira implícita a Lei 6.404/76, dispõe que o Patrimônio é constituído de:

\begin{tabular}{|c|c|}
\hline ATIVO & PASSIVO \\
\hline BENS E DIREITOS & OBRIGAÇÕES \\
\hline
\end{tabular}

Por ter o patrimônio a função de externar riquezas, é necessário ter uma base econômica de mensuração, e esta base é o valor numerário.

Um item só poderá compor o patrimônio se for mensurável em moeda corrente; não o sendo, deixa de integrar o patrimônio até que se tenha prova cabal de seu valor, sendo que este para ser mensurável em moeda corrente também tem que ser considerado como de utilidade; como exemplo podemos citar o ar que respiramos, que, muito embora seja um bem essencial para a nossa sobrevivência, não pode ser mensurável em moeda corrente.

A lei $n^{\circ}$ 6.404/76 dispõe em seu artigo 178 que o Patrimônio da Empresa será demonstrado da seguinte maneira:

\begin{tabular}{|c|c|}
\hline ATIVO & PASSIVO \\
\hline BENS E DIREITOS & OBRIGAÇÕES \\
& EXIGIBILIDADES \\
& + PATRIMÔNIO LÍQUIDO \\
\hline
\end{tabular}

\section{Passivo}

O termo passivo, por ser usado no dia-a-dia em nosso meio profissional, raramente é analisado em sua definição. Pesquisando, encontramos as seguintes definições:

Harfield definiu exigibilidades. "Num sentido restrito, exigibilidades ... são subtraendos dos ativos, ou ativos negativos. Seria lógico, portanto, preparar um balanço no qual as exigibilidades totais fossem subtraídas dos ativos totais, deixando no lado direito do balanço meramente os itens que representam a propriedade". (Accouting It's Principles and Problems, 1927) (Apud IUDÍCIBUS, Sérgio de 2000:145).

"A teoria dos fundos poderia interpretar os pas- sivos de forma diferente, como reservas ou restrições aos ativos, derivantes de considerações legais, eqüitativas, econômicas ou gerenciais." (IUDÍCIBUS, Sérgio de 2000:145).

"A visão da teoria da entidade é outra, isto é, considera as exigibilidades como reclamos contra a entidade ou, mais especificamente, contra os ativos da entidade." (IUDÍCIBUS, Sérgio de 2000:145).

"Passivo é a expressão quantitativa do patrimônio que representa a riqueza de terceiros que serviu de fonte para a formação da substância patrimonial". (SÁ, Antonio Lopes de 1998:59).

"O Passivo compreende basicamente todas as obrigações a pagar, isto é, as quantias que a empresa deve a terceiros" (Equipe de professores da FEA/USP 1998:30).

"Significa as obrigações exigíveis da empresa, ou seja, as dívidas que serão cobradas, reclamadas a partir da data do seu vencimento. É denominado também passivo exigivel, procurando-se neste caso dar mais ênfase ao aspecto da exigibilidade." (MARION, José Carlos 1998:37).

"O Passivo é uma obrigação exigivel, isto é, no momento em que a dívida vencer, será exigida (reclamada) a sua liquidação." (IUDICÍBUS/MARION 1991:34).

"Passivos são sacrifícios futuros prováveis de benefícios econômicos resultantes de obrigações presentes." (HENDRIKSEN Eldon S.; BREDA Michael F. Van 1999:410).

Portanto, em vista das definições das diferentes escolas que estudam a contabilidade, podemos concluir que os passivos são obrigações das entidades, e que estas obrigações de alguma maneira contribuíram para a formação de seu patrimônio.

Podemos dizer que, de maneira geral, o passivo é composto pelo seguinte grupo de contas: PASSIVO CIRCULANTE; PASSIVO EXIGÍVEL A LONGO PRAZO E RESULTADO DE EXERCÍCIOS FUTUROS.

Vamos comentar sobre estes grupos.

Passivo circulante

Encontramos algumas definições, tais como: "Evidencia todas as dívidas com terceiros que 
serão pagas a curto prazo: dívidas com fornecedores de mercadorias, salários a pagar, impostos a pagar, empréstimos bancários a pagar, encargos a pagar etc.." (MARION José Carlos 1998:60).

"As contas representativas das obrigações da sociedade que vencerem no exercício social seguinte. Exemplos: Fornecedores, Salários e Encargos a Pagar, Empréstimos, Debêntures, Encargos Financeiros a Pagar, Impostos a recolher, Provisão para Imposto de Renda etc." (Equipe de Professores da FEA/USP 1998: 137).

"Este grupo reúne todas as contas representativas de créditos de terceiros, de exigibilidade imediata ou quase imediata, resultantes de operações de funcionamento da empresa, vencíveis em prazos geralmente inferiores ao do ciclo operacional da empresa." (FRANCO, Hilário 1992:75).

"Compreende todas as obrigações da empresa vencíveis no prazo de um ano ou, se o ciclo operacional for maior que um ano, as obrigações vencíveis no prazo do ciclo operacional." (MATARAZZO, Dante Carmine; PESTANA, Armando Oliveira 1995:63).

"O passivo circulante é representado pelas obrigações da companhia cuja liquidação se espera que ocorra dentro do exercício social seguinte, ou de acordo com o ciclo operacional da empresa, se este for superior a esse prazo. Estas obrigações podem representar valores fixos ou variáveis, vencidos ou a vencer, em uma data ou em diversas datas futuras." (Equipe de professores da FEA USP 1986:236).

"No grupo do passivo circulante classificam-se todas as contas representativas de obrigações ou exigibilidades da companhia para com terceiros, que deverão ser pagas no decorrer do período de 12 meses seguintes à data do balanço patrimonial que estiver sendo levantado." (GOUVEIA, Nelson 1993:253).

De acordo com as definições citadas, entendemos que se consegue definir claramente o que deve ser incluído no passivo circulante, entendemos que o profissional contábil deve em primeiro lugar priorizar as informações para os administradores e usuários da contabilidade e não se basear puramente em critérios fiscais, o que restringe a utilização das provisões e previsões de modo adequado.

\section{Passivo exigível a longo prazo}

Encontramos as seguintes definições:

"Compreende as obrigações com terceiros que serão liquidadas a longo prazo. As dívidas a longo prazo normalmente se referem aos financiamentos obtidos junto às financeiras e bancos de desenvolvimento e de investimento." (MARION, José Carlos 1998: 60).

"As contas representativas das obrigações com vencimentos após o término do exercício social seguinte. Exemplos: Financiamentos, Debêntures, Encargos Financeiros a Pagar, Retenções Contratuais etc..." (Equipe de professores da FEA/USP 1998:137).

"Este grupo reúne todas as contas representativas de créditos de terceiros, de exigibilidade remota, sujeitos a planos de amortização lenta, geralmente originados de operações de financiamento ou suprimento, tais como os empréstimos por debêntures, os hipotecários e todas as dívidas com vencimento além dos prazos normais ou de praxe nos meios econômicos. Esses créditos, cuja exigibilidade ocorrerá em exercícios futuros, transformam-se em verdadeiras operações de financiamento" (FRANCO, Hilário 1992:77).

"O Exigivel a Longo Prazo compreende as obrigações da empresa vencíveis a prazo superior a um ano ou superior ao ciclo operacional da empresa. Normalmente, os créditos superiores a um ano ocorrem por contratos firmados pela empresa com instituições financeiras, como Bancos de Investimentos ou de Desenvolvimento. Excepcionalmente, podem surgir créditos de longo prazo decorrentes de negociações com fornecedores ou de parcelamento de dívidas junto ao Governo." (MATARAZZO, Dante Carmine; PESTANA, Armando Oliveira 1995:65)

"São classificadas no grupo exigível a longo prazo as contas representativas de exigibilidades com vencimento após o período de 12 meses subseqüentes à data do balanço patrimonial que estiver sendo levan- 
tado." (GOUVEIA, Nelson 1993:253).

"No passivo exigível a longo prazo serão registradas as obrigações da companhia, cuja liquidação deverá ocorrer em prazo superior a seu ciclo operacional, ou após o exercício social seguinte." (Equipe de professores da FEA/USP 1986:237).

Podemos também citar o artigo 180 da Lei 6.404 das Sociedades por ações e aplicável às demais entidades, que estabelece que:

"As obrigações da companhia, inclusive financiamento para aquisição de direitos do ativo permanente, serão classificadas no passivo circulante, quando se vencerem no exercício seguinte, e no passivo exigível a longo prazo, se tiverem vencimento em prazo maior, observado o disposto no parágrafo único do art. 179".

O parágrafo único do artigo 179 da Lei estabelece que:

"Na companhia em que o ciclo operacional da empresa tiver duração maior que o exercício social, a classificação no circulante ou longo prazo terá por base o prazo desse ciclo."

Diante das definições citadas, temos a acrescentar que neste grupo de contas, uma vez que a maioria de seus componentes serão financiamentos, a nosso ver é imprescindível o cuidado no reconhecimento de juros e encargos sobre os mesmos.

\section{Resultado de exercícios futuros}

Consideramos relevantes as seguintes definições:

"De acordo com a Lei 6.404/76, são classificadas como Resultado de Exercícios Futuros as receitas de exercícios futuros, diminuídas dos custos e das despesas a elas correspondentes." (Equipe de professores da FEA USP 1998:137).

"Compreende, pois, as contas de passivo transitório, que são apenas nominalmente passivas, constituindo receitas diferidas. Neste caso, estão as contas referentes a vendas diferidas e a receitas recebidas antecipadamente. Tais receitas se transformarão em resultado nos exercícios seguintes, dependendo ape- nas da formalidade conclusiva." (FRANCO, Hilário 1992:78).

O artigo 181 da Lei $n^{\circ} 6404$ das Sociedades por ações e aplicável às demais empresas conceitua este grupo da seguinte forma:

Art. 181. "Serão classificadas como resultados de exercício futuro as receitas de exercícios futuros, diminuidas dos custos e despesas a elas correspondentes".

"Compreende as receitas de exercícios futuros deduzidas as despesas incorridas ou a incorrer. Essas receitas são aquelas faturadas antecipadamente, em relação ao momento de sua efetiva realização. Entretanto, é preciso cuidado, a essas receitas não deve corresponder eventual devolução ou execução de obras ou produtos, pois, nesse caso, não se configuraria como receita, mas como adiantamento de cliente e se enquadraria no Passivo Exigivel (Circulante ou Longo Prazo)" (MATARAZZO, Dante Carmine; PESTANA, Armando Oliveira 1995:65 /66).

Entendemos ser esse grupo de contas um dos mais complexos e de dúbia interpretação da classe contábil.

\section{3- Mensurando o Passivo}

Ao tratarmos do passivo e sua mensuração, estaremos falando, na verdade, de exigibilidades, pois, a primeira vista, poderia se imaginar que iríamos tratar de todas as contas que figuram do lado direito do balanço patrimonial.

"Segundo o Fasb, um passivo possui as três características essenciais seguintes:

1. Contém uma obrigação ou responsabilidade presente com uma ou mais entidades, prevendo liquidação pela transferência futura provável ou pelo uso de ativos numa data especificada ou determinável, na ocorrência de um evento predeterminado, ou assim que seja solicitada.

2. A obrigação ou responsabilidade compromete dada entidade, permitindo-lhe pouca ou nenhuma liberdade para evitar o sacrifício futuro.

3. A transação ou outro evento que obriga a entidade já ocorreu. 
"Se apenas uma dessas características estiver ausente, um passivo contábil não poderá ser reconhecido." (HENDRIKSEN, Eldon S.; BREDA, Michael F.Van 1999:286).

Pode-se dizer também sobre o passivo: "Do ponto de vista interpretativo, os passivos poderiam ser definidos como obrigações ou compromissos de uma empresa no sentido de entregar dinheiro, bens ou serviços a uma pessoa, empresa ou organização externa em alguma data futura. Tal como a definição de um ativo, e pelo mesmo motivo, essa definição não faz menção da necessidade de uma transação prévia. Como ocorre também com a definição de ativos, essa definição permite que problemas de mensuração sejam tratados separadamente. Em particular, não exclui o reconhecimento de perdas em potencial como passivos, registrando-os a seu valor esperado. Um esquema como esse parece ser desesperadamente necessário, em vista da crise de associações de poupança e empréstimo, na qual bilhões de dólares em garantias não foram informadas como passivos em potencial, porque julgava-se que a inadimplência era uma possibilidade remota." (HENDRIKSEN, Eldon S.; BREDA, Michael F. Van 1999: 287/288).

Podemos dizer que o grande problema da mensuração do passivo não está em sua avaliação, e sim no quando reconhecê-lo e registrá-lo.

\section{Composição das exigibilidades}

que deve ou não ser incluído como exigibilidade é uma questão muito discutida; alguns autores entendem que só devemos incluir as dívidas efetivas, outros entendem que devemos incluir valores devidos, caso não honrarmos com o cumprimento de alguma obrigação.

Vamos citar a visão de alguns órgãos e autores para melhor compreender a questão:

"O Comitê de Princípios da American Accouting Association considerava que as exigibilidades deveriam ser obrigações legais, mas nem todas as obrigações legais são exigibilidades, na data do balanço. Assim, em 1957, definia que os interesses dos credores (exigibilidades) são reclamos contra a entidade e derivam de atividades passadas ou eventos que, usualmente, requerem, para sua satisfação, o gasto de recursos corporativos". (Apud IUDÍCIBUS, Sérgio de 2000:146).

Canning (The Economics of Accoutancy, 1929) utilizou uma frase muito rebuscada para expressar o que deveria ficar de fora ou ser incluído nas exigibilidades:

"Uma exigibilidade é um serviço avaliável em dinheiro, que um proprietário é obrigado a prestar por uma norma legal ou eqüitativa para uma segunda pessoa ou conjunto de pessoas, desde que não seja uma compensação incondicional por serviços específicos de igual ou maior valor monetário devidos por esta segunda pessoa ao proprietário." (Apud IUDÍCIBUS, Sérgio de 2000:146).

"A definição é complexa e preferimos agora expressar nosso ponto de vista:

1. As exigibilidades deveriam referir-se a fatos já ocorridos (Transações ou Eventos), normalmente a serem pagas em um momento específico futuro, podendo-se, todavia, reconhecer certas exigibilidades em situações que, pelo vulto do cometimento que podem acarretar para a entidade (mesmo que os eventos caracterizem a exigibilidade legal apenas no futuro), não podem deixar de ser contempladas.

Poderiam estar incluídos nesta última categoria, digamos, o valor atual das indenizações futuras ou provisionamentos para pensão, no caso de a entidade ter obrigação por tais pagamentos futuros.

1. Note-se, todavia, que, embora os fatos que provocam a exigibilidade legal se configurem às vezes no futuro, de alguma forma o fato gerador da exigibilidade está relacionado a eventos passados ou presentes, não se podendo apenas prever exatamente quanto e quando, senão recorrendo a cálculos previsionais e atuariais.

2. Por outro lado, se é prática comercial comum indenizar, total ou parcialmente, a terceiros por eventos que, mesmo não sendo considerados obrigações legais, de certa forma foram devidos a falhas de cumprimento de condições usuais de comércio (devoluções etc.), seria viável o provisionamento de tais encargos. Não podemos esquecer que boa parte das exigibilidades está 
associada ao reconhecimento de despesas. Para reconhecer receita é necessário ter condições para estimar as despesas associadas, mesmo que o desembolso ocorra apenas no futuro, em um ponto indeterminado." (IUDÍCIBUS, Sérgio de 2000:146/147).

"Passivos são sacrifícios futuros prováveis de benefícios econômicos resultantes de obrigações presentes. O patrimônio dos acionistas é o que sobra após subtrair passivos de ativos." (HENDRIKSEN, Eldon S.; BREDA, Michael F.Van, 1999:409)

A nosso ver, deveremos incluir como exigibilidade todo valor referente a obrigações assumidas, ou que a entidade será obrigada a assumir (processos judiciais e trabalhistas), de maneira a possibilitar uma visão correta do patrimônio por parte do administrador e usuários.

\section{Reconhecendo as exigibilidades}

Sobre o momento do reconhecimento das exigibilidades, podemos citar:

"No caso da maioria dos passivos, o momento em que o reconhecimento ocorre é bastante definido, porque a obrigação resulta de um contrato em que o valor e a data de pagamento da obrigação acham-se especificados ou são determináveis em função das condições do contrato.

Entretanto, em alguns casos, o valor a ser pago depende de eventos futuros, tais como, o nível de faturamento bruto com o uso de bens arrendados. Em tais casos o passivo existe, muito embora o valor deva ser representado em termos de equivalentes certos, ou por meio de um intervalo de valores prováveis. No caso de possibilidade de perda, o SFAS 5 dá a entender que existe um passivo que deve ser contabilizado, caso a magnitude da perda possa ser razoavelmente estimada. Portanto, de um ponto de vista semântico, e do ponto de vista de usuários de demonstrações financeiras, uma obrigação deve ser classificada como passivo, caso possa ser razoavelmente medida, ou se um intervalo significativo de valores ou probabilidades possa ser a ela atribuído." (HENDRIKSEN, Eldon S.; BREDA Michael F. Van 1999:413).
"Contudo, o momento que a transação ocorre nem sempre é claro" (HENDRIKSEN, Eldon S.; BREDA Michael F. Van 1999:413).

"Na verdade, a necessidade de reconhecer o ativo ou a despesa é geralmente o motivo crucial para o reconhecimento do passivo." (HENDRIKSEN, Eldon S.; BREDA Michael F. Van 1999:413).

"Contudo, no caso de uma perda decorrente de um direito contra a empresa, sem um benefício corrente ou futuro para ela, o foco do reconhecimento deverá vir do próprio passivo. $\mathrm{O}$ valor da obrigação e o momento de seu reconhecimento determinam o valor e o momento do reconhecimento da perda. Tão logo a obrigação torna-se definida e passível de estimação, ela deve ser reconhecida, portanto, sendo a perda contabilizada." Grifos nossos. (HENDRIKSEN, Eldon S.; BREDA, Michael F. Van 1999:413).

"Não há dúvida de que o reconhecimento de uma despesa é o elemento mais importante para o reconhecimento de um passivo, pois irá afetar o cálculo do lucro do período. Por outro lado, se ocorrer uma perda extraordinária, é preciso levá-la em consideração a fim de reportar o resultado não operacional. Se um ativo específico é recebido pela empresa, e não pago à vista, é necessário reportar a exigibilidade relacionada, a fim de evidenciar claramente sua posição financeira no balanço." (IUDÍCIBUS, Sérgio de 2000:147).

De acordo com o estudo realizado entre os autores mais conhecidos, a respeito do momento do reconhecimento da exigibilidade, notamos que existe uma dificuldade no momento do reconhecimento, o que normalmente é resolvido pela contabilização da contrapartida da exigibilidade, e alertamos para a necessidade do cuidado e precisão no registro dos mesmos, para não distorcer resultados e apresentar uma visão do patrimônio no momento certo de maneira a permitir atitudes da administração.

\section{Exigibilidades contingentes}

Para comentarmos sobre exigibilidades contingentes, podemos definir o que é perda contin- 
gente, como segue:

"Uma condição ou situação existente, um conjunto de circunstâncias envolvendo incerteza quanto a ganhos e perdas possíveis... para uma empresa, que será finalmente dirimida quando um ou mais eventos futuros ocorrerem ou deixarem de ocorrer. A resolução da incerteza poderá confirmar a existência de um passivo."(HENDRIKSEN, Eldon S.; BREDA, Michael F. Van, 1999:288).

"O SFAS 5 diz que tais perdas contingentes devem ser reconhecidas como passivos se:

1. satisfazem a definição de passivo;

2. a probabilidade de ocorrência do evento futuro é relativamente elevada;

3. a perda contingente pode ser razoavelmente estimada" (HENDRIKSEN, Eldon S.; BREDA, Michael F. Van, 1999:288).

"Obrigações decorrentes de garantias constituem um exemplo de passivos contingentes, pois um evento, a quebra do produto, ainda está para ocorrer. São reconhecidas porque é alta a probabilidade de que alguns pagamentos sejam necessários, muito embora o valor total precise ser estimado." (HENDRIKSEN, Eldon S.; BREDA, Michael F. Van, 1999: 289).

Hendriksen resume o assunto sobre passivo contingente da seguinte maneira: "Regras de reconhecimento semelhantes aplicam-se a todos os ativos e passivos. Em geral, para que um ativo ou passivo seja reconhecido, o recurso ou a obrigação deve satisfazer a definição de ativo ou passivo". (HENDRIKSEN, Eldon S.; BREDA, Michael F. Van, 1999:289).

"Na definição clássica, uma exigibilidade contingente é uma obrigação que pode surgir, dependendo da ocorrência de um evento futuro." (IUDÍCIBUS, Sérgio de 2000:148).

Basicamente, notamos que na exigibilidade contingente, caso exista condições de estimar o valor e garantir com pouca margem de erro que a empresa será obrigada a assumir o compromisso, devemos registrá-lo no passivo, caso contrário devemos citar o evento nas notas explicativas.

Avaliação e resumo das exigibilidades

"Para as exigibilidades monetárias, o valor de ba- lanço deveria ser determinado pelo valor presente dos montantes a serem pagos no futuro. Entretanto, no que se refere às exigibilidades a curto prazo, se o montante do desconto não for relevante, poderiam ser deixadas pelo valor nominal. É preciso notar, todavia, que, se pudermos pagar as exigibilidades anteriormente ou na data do vencimento, com desconto, o valor atual da alternativa de menor valor deveria ser o valor corrente das exigibilidades. No caso de exigibilidades de longo prazo, o valor do desconto é normalmente relevante e, a rigor, o valor presente de tais vencimentos futuros deveria ser calculado." (IUDÍCIBUS, Sérgio de 2000: 148).

Compreendemos que o valor das exigibilidades deve ser apurado na data em que for demonstrado, ou seja, este é o valor que devemos neste momento.

Pelo que conseguimos entender de nossa pesquisa, uma exigibilidade deve ser registrada quando o fato gerador já tenha ocorrido e deve existir condições básicas de definir sua data, seu vencimento e seu valor neste momento. A obrigação deve ser registrada, desde que o profissional tenha razoável certeza de que no futuro teremos que fazê-lo, como, por exemplo, as causas judiciais e os passivos contingentes.

\section{Considerações finais}

De acordo com o material examinado, podemos dizer que para o usuário da contabilidade é imprescindível o acompanhamento do Passivo de qualquer instituição, desde que os profissionais tenham as informações e o conhecimento necessários para sua correta mensuração.

Lamentamos observar o nível de desconhecimento por parte dos usuários de uma maneira geral das informações deste grupo, e de como com as mesmas é possível a análise e acompanhamento do nível de obrigações de qualquer companhia, e verificar, ao mesmo tempo, que nossa classe é tratada como uma mera formalidade legal; seria por falta de marketing de nossos serviços e relatórios ou por omissão de nossa categoria? 


\section{REFERÊNCIAS BIBLIOGRÁFICAS}

EQUIPE DE PROFESSORES DA FEA/USP. Contabilidade Introdutória. 9 ed. São Paulo: Atlas, 1998

EQUIPE DE PROFESSORES DA FEA/USP. Manual da Contabilidade das Sociedades por Ações. 2. ed. São Paulo: Atlas, 1986 FRANCO, Hilário. Estrutura, Análise e Interpretação de Balanço. 15. ed. São Paulo: Atlas, 1992.

GOUVEIA, Nelson. Contabilidade Básica. 2. ed. São Paulo: Harbra, 1993.

HENDRIKSEN, Eldon S.; BREDA, Michael F. Van. Teoria da Contabilidade. Trad. Antonio Zoratto Sanvicente. 5 ed. São Paulo: Atlas, 1999.

IUDÍCIBUS, Sérgio de. Teoria da Contabilidade. 6. ed. São Paulo : Atlas, 2000.

MARION, José Carlos. Contabilidade Básica. 6. ed. São Paulo: Atlas, 1998

MARION, José Carlos; IUDíCIBUS Sérgio de. Curso de Contabilidade para não contadores. São Paulo: Atlas, 1991.

MATARAZZO, Dante Carmine; PESTANA, Armando Oliveira. Análise financeira de Balanços. 3. ed. São Paulo: Atlas, 1995.

SÁ, Antonio Lopes de. Teoria da Contabilidade. São Paulo: Atlas, 1998. 